\title{
The assessment of faecal flora in patients with inflammatory bowel disease by a simplified bacteriological technique
}

\author{
M. H. GIAFFER, C. D. HOLDSWORTH* and B. I. DUERDEN†
}

Gastroenterology Unit, Royal Hallamshire Hospital, Sheffield S10 2JF and +Department of Experimental and Clinical Microbiology, University of Sheffield Medical School, Beech Hill Road, Sheffield S102RX

\begin{abstract}
Summary. A semi-quantitative bacteriological method was used to study faecal flora in 42 patients with Crohn's disease, 37 with ulcerative colitis and 21 healthy controls. Faecal homogenates were plated on primary isolation plates by a technique that allowed the growth of various microbial isolates to be assessed on a visual $1+-5+$ score. This method was first calibrated against a standard quantitative bacteriological technique, which confirmed the reliability and reproducibility of the results obtained by the simpler method. Patients with clinically active Crohn's disease (22) had significantly higher total aerobe scores than patients with quiescent disease $(20)(\mathrm{p} \leq 0.006)$ or ulcerative colitis $(\mathrm{p} \leq 0.04)$ or normal controls $(\mathrm{p} \leq$ 0.02). The scores of Escherichia coli were parallel to those of total aerobes. Lactobacillus and bifidobacteria scores were significantly reduced in patients with Crohn's disease compared to those with ulcerative colitis and controls. The anaerobic flora in both Crohn's disease and ulcerative colitis was indistinguishable from that of controls. Bacteroides vulgatus and $B$. fragilis were the predominant bacteroides in all groups. Patients with ulcerative colitis, regardless of disease activity, harboured faecal flora that did not differ from that of normal controls. The abnormal faecal flora in Crohn's disease did not correlate with established clinical and laboratory indicators of disease activity.
\end{abstract}

\section{Introduction}

The quantitative surface viable count technique described by Miles et $a l^{1}$ is the only common bacteriological method applied for the enumeration of the various components of the faecal microbial flora. It has the disadvantage of being laborious and timeconsuming and may influence the number of faecal samples that can be analysed in a busy laboratory. Direct microscopic counting of the faecal microbes by microscopy has also been used to evaluate the composition of faecal flora but this does not differentiate between dead and viable bacteria and studies comparing the two bacteriological methods have frequently given conflicting results. ${ }^{2}$ Neither method can be reproduced with accuracy; direct microscopic counting is the least reliable. For the analysis of a large number of faecal samples, the availability of a simple, reliable and reasonably accurate bacteriological method is desirable.

A semi-quantitative microbiological method is

Received 12 Sep. 1990; accepted 23 Dec. 1990

* Correspondence should be sent to Dr C. D. Holdsworth.

$\uparrow$ Present address: Department of Medical Microbiology, University of Wales College of Medicine, Heath Park, Cardiff CF4 4XN. described that can be used for the assessment of faecal microbial flora in health and disease. This gives results comparable to those obtained by the standard surface viable count, a technique which has been widely used to enumerate bacteria in faecal specimens. ${ }^{3-6}$ The results of the application of this method to determine the composition of the faecal flora in patients with inflammatory bowel disease are also presented.

\section{Materials and methods}

\section{Patients}

Twenty-nine patients with inflammatory bowel disease and 21 healthy individuals were studied. In all patients the disease was diagnosed by standard clinical, radiological and histological criteria. ${ }^{7}$

Forty-two patients had Crohn's disease. In 22 of these ( 16 females and 6 males; mean age 38 years), the disease was considered to be active. Disease activity was assessed by the presence of significant symptoms, (e.g., diarrhoea, abdominal pain, weight loss), abnormal laboratory tests generally accepted as reflecting active gut inflammation ${ }^{8}$ and a Crohn's Disease Activity Index (CDAI) of $>150 .^{9}$ Five patients had 
Crohn's disease that recurred at the site of a previous ileo-colonic anastomosis; eight had small bowel and seven large bowel disease and, in two, both the large and small bowel were affected. The remaining 20 patients ( 15 female and five male; mean age 50 years) had quiescent Crohn's disease (CDAI $\leq 150$ ). The disease was present in the anastomosis in six patients, limited to the small bowel in five, confined to the large bowel in six and involved both small and large bowel in three.

None of these patients had fistulae, severe perianal disease or overt sepsis. In 13 patients, of whom 10 had active disease and three were quiescent, intestinal strictures were demonstrated radiologically. Seven patients, four with active and three with quiescent disease, were taking sulphasalazine in a mean daily dose of $2 \mathrm{~g}$, and a further two were receiving other 5amino-salicyclic acid (5-ASA) drugs. The remaining 33 patients had not been prescribed any medication.

Thirty-seven patients had ulcerative colitis. The disease was considered to be active in 18 patients $(10$ female and eight male, mean age 37 years). Disease activity was defined by the criteria of Truelove and Witts. ${ }^{10}$ Symptoms were not severe enough in any of these patients to require hospital admission. Eleven patients had their first acute attack of colitis. The disease was confined to the rectum in four patients, limited to the left colon in six and diffusely affected the large bowel in eight. The remaining 19 patients ( 12 females and seven males, mean age 50 years) had quiescent disease that affected only the rectum in seven patients, the left colon in eight and most of the colon in four. Eleven patients, (five with active disease and six who were quiescent), were receiving sulphasalazine and 14 others were taking 5-ASA preparations; the remaining patients had not been prescribed any medication.

The control group was 21 healthy laboratory workers ( 10 female and 11 male, mean age 35 years). All were understood to be in good health and none was known to have gastrointestinal disease.

None of the patients studied had received antibiotics for at least 4 weeks before the faecal samples were collected and all were taking normal unrestricted diets.

\section{Bacteriological methods}

Freshly voided faeces $(10-20 \mathrm{~g})$ were collected in a sterile $20-\mathrm{ml}$ screw-top container. The samples that were not analysed immediately were stored at $4^{\circ} \mathrm{C}$ for no longer than $24 \mathrm{~h}$, a period during which the number of viable organisms is known not to change significantly $;{ }^{11}$ we confirmed this. A $1-\mathrm{g}$ (wet weight) sample of faeces was dispensed in $9 \mathrm{ml}$ of sterile phosphatebuffered saline, $\mathrm{pH} 7 \cdot 3$, and thoroughly mixed. Subsequent processing depended on whether a quantitative or a semi-quantitative technique was to be applied.
Semi-quantitative (standard loop) method. A sterile 2-mm standard loop was used to plate the faecal homogenate on to the primary isolation plates. The charged loop was used to initiate a set of streaks across the plate (fig. 1). The overlap between the sets was kept constant at $c .1 \mathrm{~cm}^{2}$. The technique allowed a semi-quantitative assessment of bacteria on a $1+-5+$ scale, similar to that applied by McGeachie and Kennedy to urine samples ${ }^{12}$ and Rotimi et al. to neonatal faeces. ${ }^{13}$ The media used, the groups of organisms for which each was selective and the incubation conditions are shown in table I.

The primary isolation plates were incubated at $37^{\circ} \mathrm{C}$ aerobically with $\mathrm{CO}_{2} 10 \%$ or anaerobically $\left(\mathrm{N}_{2} 80 \%\right.$, $\mathrm{H}_{2} 10 \%, \mathrm{CO}_{2} 10 \%$ ) in an anaerobic cabinet (DW Scientific, Shipley, W. Yorks). Aerobic cultures were examined after $24 \mathrm{~h}$ and anaerobic cultures after 48$96 \mathrm{~h}$. Representative colonies of particular morphology, were examined by Gram's stain, and subcultured on blood agar and were subsequently identified by standard tests. ${ }^{14}$ Bacteroides spp. were identified as described by Duerden et al. ${ }^{15}$

Quantitative (surface viable count) method. The semiquantitative loop technique was calibrated against a surface viable count. ${ }^{3}$ Briefly, $1-\mathrm{ml}$ samples from 10 fold dilutions of the faecal homogenate were spread evenly on the surface of the primary isolation plates with a sterile glass rod. After aerobic or anaerobic incubation, the number of cfu on each plate was counted with an electronic colony counter.

\section{Statistical analysis}

The semi-quantitative counts of faecal microorganisms were expressed as a growth score $(1+$ $-5+$ ). Data are presented as mean (SEM) score. The Mann-Whitney and $\chi^{2}$ tests were used to compare the bacterial scores between different groups. The corre-

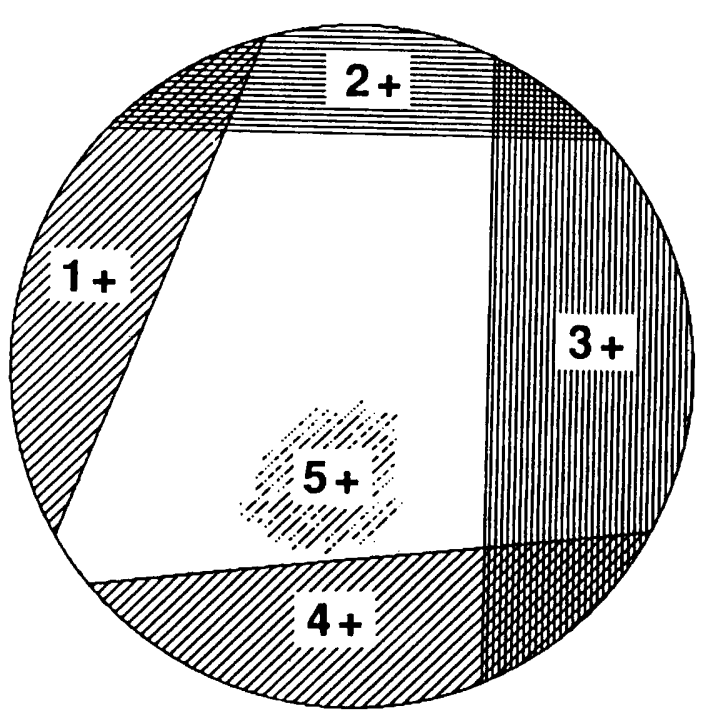

Fig. 1. Plating technique in the standard loop method; overlap was kept constant $\left(1 \mathrm{~cm}^{2}\right)$. 
Table I. Media for bacterial isolation from faeces

\begin{tabular}{|c|c|c|}
\hline Medium & Incubation conditions & Bacteria investigated \\
\hline $\begin{array}{l}\text { Blood Agar } \\
\text { (Oxoid Columbia Agar Base with defibrinated } \\
\text { horse blood, Wellcome, } 7 \cdot 5 \% \text { ) }\end{array}$ & $37^{\circ} \mathrm{C}$ Aerobic & Aerobes and facultative organisms \\
\hline Sabourauds Agar (Oxoid) & $37^{\circ} \mathrm{C}$ Aerobic & Yeasts \\
\hline MacConkey Agar (Oxoid) & $37^{\circ} \mathrm{C}$ Aerobic & Enterobacteria, enterococci \\
\hline Rogosa Agar (Oxoid) & $37^{\circ} \mathrm{C}$ Anaerobic & Lactobacilli \\
\hline $\begin{array}{l}\text { Reinforced Clostridial Cotton Blue Agar } \\
\text { (R.C.M., Oxoid, with New Zealand agar } 0.7 \% \\
\text { and Cotton Blue } 1 \% \text {, pH 5) }\end{array}$ & $37^{\circ} \mathrm{C}$ Anaerobic & Bifidobacteria \\
\hline Bacteroides Medium $^{15}+$ kanamycin & $37^{\circ} \mathrm{C}$ Anaerobic & Anaerobes, clostridia anaerobic gram-positive cocci \\
\hline $\begin{array}{l}\text { Bacteroides Medium + kanamycin + vanco- } \\
\text { mycin }\end{array}$ & $37^{\circ} \mathrm{C}$ Anaerobic & Bacteroides \\
\hline Blood Agar & $37^{\circ} \mathrm{C}$ Anaerobic & Anaerobes and facultative organisms \\
\hline
\end{tabular}

lation between the faecal flora and the clinical and laboratory activity indices was determined by Spearman's equation and presented as correlation coefficient $\left(r_{s}\right)$ and the associated probability $(p)$. The results of the quantitative methods are presented as $\log _{10}$ mean viable counts/g of faeces.

\section{Results}

\section{Validation of the standard loop method}

Ten faecal samples were examined by both standard loop and surface viable count methods. The results are shown in fig. 2. A bacterial score of $1+$ corresponded to a mean count $\log _{10} 5 \cdot 4$ SEM $0 \cdot 16,2+$ to $6 \cdot 8$ SEM $0 \cdot 1$, a $3+$ to $7 \cdot 4$ SEM $0 \cdot 15,4+$ to $8 \cdot 8$ SEM $0 \cdot 1$ and $5+$ to $9 \cdot 5$ SEM $0 \cdot 1$. A change in the bacterial score by a factor of $1+$ corresponded in most cases to a change in the count by $\log _{10} 1$ (fig. 2). The reproducibility of the standard loop method was evaluated by examining the bacterial scores obtained from the same sample by different observers. Similar results were obtained with all five samples examined.

\section{Bacteriological scores in Crohn's disease and ulcerative colitis}

The mean (and SEM) bacterial scores for healthy subjects and those with Crohn's disease and ulcerative colitis are shown in table II.

There was a significant increase in the total numbers of aerobes in patients with active Crohn's disease compared to quiescent Crohn's disease ( $p \leq 0.006)$, ulcerative colitis $(\mathrm{p} \leq 0.04)$ and normal controls $(\mathrm{p} \leq$ 0.02 ), and in the scores of Escherichia coli in active compared to inactive Crohn's disease $(p \leq 0.04)$, ulcerative colitis $(\mathrm{p} \leq 0.007)$ and normal controls $(\mathrm{p} \leq$ 0.02). Klebsiella and Proteus spp., viridans streptococci and yeasts were isolated from patients with Crohn's disease as frequently as from healthy persons. How-

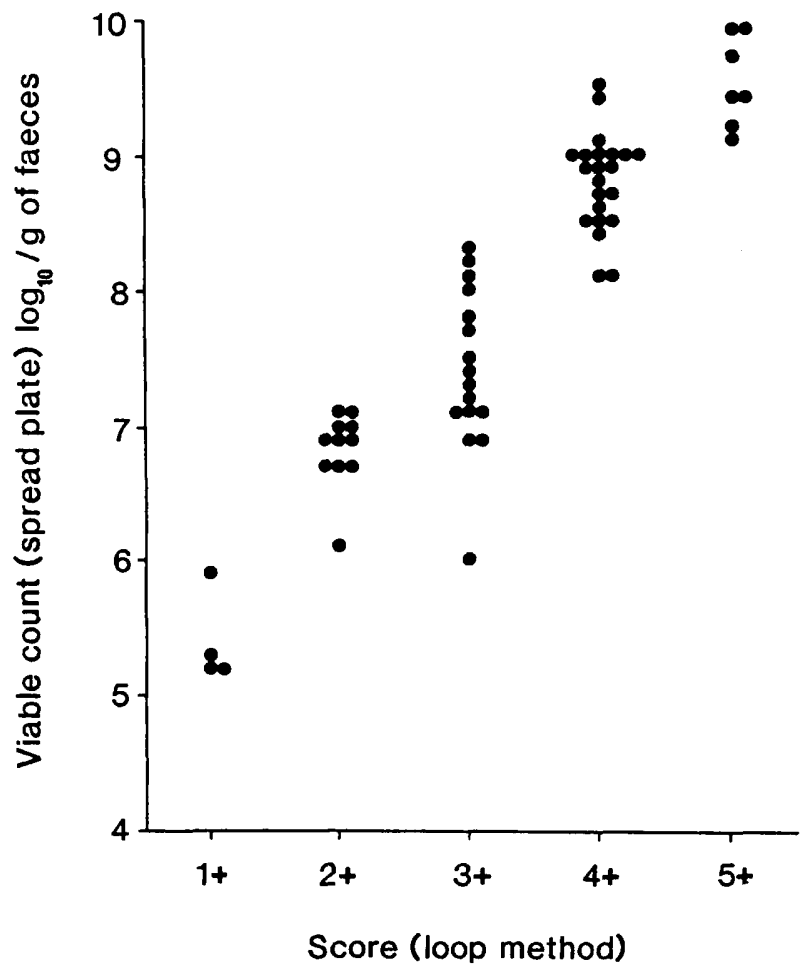

Fig. 2. Correlation between standard loop and surface viable count methods for 60 bacterial isolates from 10 faecal samples.

ever, Enterococcus faecalis was isolated from six (27\%) patients with active Crohn's disease compared to 11 (55\%) patients with quiescent Crohn's disease ( $\mathrm{p} \leq$ $0.05), 21(62 \%)$ with ulcerative colitis $(\mathrm{p} \leq 0.02)$ and 10 $(48 \%)$ normal controls ( $\mathrm{p} \leq 0 \cdot 1)$. In those who harboured these organisms, the isolate scores were similar in all groups studied. Diphtheroid bacilli were isolated from six patients with acute Crohn's disease but from none of 20 with quiescent Crohn's disease.

Total anaerobic and bacteroides scores were similar in Crohn's disease, ulcerative colitis and controls. Lactobacillus scores were generally lower in Crohn's disease, particularly when the disease was quiescent when the difference from controls was significant 
Table II. Bacterial scores in patients with inflammatory bowel disease and controls

\begin{tabular}{|c|c|c|c|c|c|c|c|c|c|c|}
\hline \multirow{3}{*}{ Bacteria isolated } & \multicolumn{10}{|c|}{ Number of patients with isolates ( $n$ ) and their mean (SEM) scores } \\
\hline & \multicolumn{2}{|c|}{ Active Crohn's } & \multicolumn{2}{|c|}{ Quiescent Crohn's } & \multicolumn{2}{|c|}{ Active UC } & \multicolumn{2}{|c|}{ Quiescent UC } & \multicolumn{2}{|c|}{ Controls } \\
\hline & $\mathbf{n}$ & Score & $\mathbf{n}$ & Score & $\mathbf{n}$ & Score & $\mathbf{n}$ & Score & $\mathbf{n}$ & Score \\
\hline Total aerobes & 22 & $* 4 \cdot 1(0 \cdot 2)$ & 20 & $3.4(0 \cdot 2)$ & 18 & $3 \cdot 7(0 \cdot 2)$ & 19 & $3 \cdot 6(0 \cdot 2)$ & 21 & $3.4(0 \cdot 2)$ \\
\hline E. coli & 22 & $+3 \cdot 7(0 \cdot 1)$ & 20 & $3 \cdot 1(0 \cdot 2)$ & 18 & $2 \cdot 9(0 \cdot 3)$ & 19 & $3.0(0 \cdot 2)$ & 21 & $3 \cdot 1(0 \cdot 2)$ \\
\hline Enterococci & 10 & $3.6(0.3)$ & 12 & $3 \cdot 2(0 \cdot 2)$ & 13 & $3 \cdot 1(0 \cdot 3)$ & 10 & $3 \cdot 3(0 \cdot 2)$ & 12 & $3.5(0 \cdot 2)$ \\
\hline Total anaerobes & 22 & $4 \cdot 7(0 \cdot 2)$ & 20 & $4 \cdot 5(0 \cdot 2)$ & 18 & $4.5(0 \cdot 2)$ & 19 & $4 \cdot 7(0 \cdot 2)$ & 21 & $4.9(0.05)$ \\
\hline B. vulgatus & 17 & $4 \cdot 6(0 \cdot 1)$ & 9 & $4 \cdot 3(0 \cdot 2)$ & 10 & $4 \cdot 4(0 \cdot 1)$ & 15 & $4 \cdot 7(0 \cdot 1)$ & 13 & $4 \cdot 7(0 \cdot 1)$ \\
\hline B. fragilis & 7 & $3.8(0.5)$ & 7 & $4 \cdot 1(0 \cdot 3)$ & 4 & $4 \cdot 6(0.4)$ & 3 & $4 \cdot 7(0 \cdot 3)$ & 6 & $4 \cdot 8(0 \cdot 2)$ \\
\hline Anaerobic lactobacilli & 21 & $2 \cdot 3(0 \cdot 3)$ & 9 & $\$ 1.4(0.4)$ & 15 & $2 \cdot 1(0 \cdot 4)$ & 19 & $2.8(0.2)$ & 17 & $2 \cdot 9(0 \cdot 2)$ \\
\hline Bifidobacteria & 22 & $\ddagger 3 \cdot 2(0 \cdot 2)$ & 10 & $2 \cdot 8(0 \cdot 4)$ & 15 & $4 \cdot 1(0 \cdot 2)$ & 18 & $3.6(0 \cdot 3)$ & 17 & $4 \cdot 0(0 \cdot 3)$ \\
\hline Clostridia & 16 & $4 \cdot 4(0 \cdot 1)$ & 5 & $4.0(0.4)$ & 8 & $4 \cdot 1(0.4)$ & 14 & $4.2(0.2)$ & 5 & $4.5(0 \cdot 2)$ \\
\hline
\end{tabular}

UC, ulcerative colitis.

* Significantly different from controls ( $p \leq 0.02)$, quiescent Crohn's ( $p \leq 0.006)$ and $U C(p \leq 0.04)$.

$\dagger$ Significantly different from controls ( $p \leq 0.006)$, quiescent Crohn's ( $\leq \leq 0.04)$ and UC ( $p \leq 0.007)$.

¥ Significantly different from controls $(\mathrm{p} \leq 0.007)$ and $\mathrm{UC}(\mathrm{p} \leq 0 \cdot 01)$.

$\S$ Significantly different from controls ( $\mathrm{p} \leq 0.002)$.

$(\mathrm{p} \leq 0.002)$. The scores of bifidobacteria were lower in Crohn's disease than in patients with ulcerative colitis $(\mathrm{p} \leq 0.01)$ and controls ( $\leq 50.007)$; active disease was associated with relatively higher scores than quiescent disease, although the difference was not significant. Bacteroides vulgatus and $B$. fragilis were the predominant strictly anaerobic gram-negative bacilli isolated from the stools of patients with Crohn's disease and controls. The scores of both organisms in patients with isolates were similar.

These observations remained tenable even when patients taking sulphasalazine were excluded. The changes in faecal flora in Crohn's disease were independent of disease location, resection of the ileocaecal valve, or the presence of intestinal strictures. Table III shows that except for a correlation between the bifidobacteria score and the platelet count, which was considered to be a chance finding, the abnormal faecal flora in patients with active Crohn's disease did not correlate with established clinical and laboratory indices.

The faecal flora of patients with moderately active ulcerative colitis was not significantly different from that of healthy individuals and patients with quiescent disease (table II). The only difference was that a greater number of patients with ulcerative colitis had diphtheroids than patients with Crohn's disease or controls. As in Crohn's disease and healthy persons, the predominant Bacteroides spp. in patients with ulcerative colitis were $B$. vulgatus and $B$. fragilis. Both species were present in similar numbers in both patient groups.

\section{Discussion}

Bacteriological methods applied to estimate bacterial counts in faeces have been limited hitherto to the conventional viable surface count of Miles et al. ${ }^{1}$ and its modified "spreading" method. This technique is subject to error, cumbersome and time-consuming, thus limiting the number of samples that can be analysed. This is particularly relevant to studies of the faecal flora in patients with inflammatory bowel disease when a larger number of subjects may need to be analysed to reveal small alterations in the composition of the faecal flora. The simplified bacteriological method described represents a reliable alternative to the pour-plate method. ${ }^{3}$ The results of the calibration studies showed that the bacterial counts obtained by both methods were comparable. However, the new method has the advantage of being less tedious, allowing the examination of a larger number of faecal samples. Furthermore, changes in bacterial counts by $\log _{10} 1$ or more could be detected as reliably by this method as by the conventional technique. A maximum score of $5+$ corresponded to a bacterial count of $\log _{10}$ 9. This approximates to the total number of bacteria cultured from faeces reported in other studies. ${ }^{6}$ On the other hand, a score of $1+$ represents a bacterial count in the range of $\log _{10} \leq 5$. Most bacteria in the faeces are present in counts of $\log _{10}>5$ and, therefore, would have been detected by either method.

Previous reports of faecal flora in inflammatory bowel disease all reported on a restricted number of patients, presumably due to the limitations of bacteriological methodology then available and it is not surprising, therefore, that a general consensus could not be reached from these studies. The series reported by Gorbach et al. ${ }^{4}$ included 18 patients with ulcerative colitis and eight with Crohn's disease. Using the pourplate method they found increased total aerobic and coliform counts in the faeces of patients with Crohn's disease and in those with severe diffuse ulcerative colitis. Keighley et al..$^{5}$, also found increased $E$. coli counts in operative samples from the ileum and colon of patients with Crohn's disease. On the other hand, West et al. ${ }^{6}$ reported that the faecal flora in 21 patients with ulcerative colitis and five with Crohn's disease did not differ significantly from normal controls. In 
Table III. Correlation between the abnormal faecal flora scores and clinical and laboratory indicators of disease activity in Crohn's disease

\begin{tabular}{l|ccrrrr}
\hline \multirow{2}{*}{$\begin{array}{l}\text { Activity } \\
\text { indicator }\end{array}$} & \multicolumn{2}{|c}{ Total aerobes } & \multicolumn{2}{c}{ E. coli } & \multicolumn{2}{c}{ Bifidobacteria } \\
\cline { 2 - 7 } & \multicolumn{1}{c}{$\mathrm{r}_{\mathrm{s}}$} & $\mathrm{p}$ value & $\mathrm{r}_{\mathrm{s}}$ & $\mathrm{p}$ value & $\mathrm{r}_{\mathrm{s}}$ & \multicolumn{2}{c}{$\mathrm{p}$ value } \\
\hline CDAI & 0.009 & 0.9 & 0.287 & 0.2 & -0.118 & 0.6 \\
Haemoglobin & -0.2 & 0.6 & -0.261 & 0.3 & -0.195 & 0.6 \\
Platelet count & 0.239 & 0.3 & 0.037 & 0.9 & 0.481 & 0.03 \\
Serum albumin & -0.279 & 0.2 & -0.137 & 0.6 & -0.135 & 0.5 \\
C-RP & 0.234 & 0.3 & 0.231 & 0.3 & -0.006 & 0.9 \\
AGP & 0.307 & 0.2 & 0.173 & 0.5 & 0.203 & 0.6 \\
\hline
\end{tabular}

CDAI, Crohn's Disease Activity Index; C-RP, C-reactive protein; AGP, Alpha-one acid glycoprotein; $r_{s}$, correlation coefficient; $p$ value, associated probability.

the present study the composition of the faecal fiora in 42 patients with Crohn's disease and 37 others with ulcerative colitis was examined by the simplified loop method. Significant alterations in the faecal flora were limited to patients with active Crohn's disease; the increase in the numbers of aerobes and $E$. coli were the most prominent changes. Furthermore, the scores of bifidobacteria and anaerobic lactobacilli were reduced in patients with Crohn's disease. In contrast, the anaerobic flora, particularly the bacteroides component, remained relatively stable in patients with inflammatory bowel disease. Local factors, such as the presence of bowel resection did not seem to affect the composition of the faecal flora, a finding also previously confirmed. ${ }^{5}$

Patients with ulcerative colitis, regardless of disease activity, had faecal flora similar to that of the healthy controls, a finding consistent with previous reports. ${ }^{5,6}$ The 11 patients with newly diagnosed colitis had faecal flora similar to those with long-standing disease. The absence of severe diarrhoeal symptoms in the majority of patients with active colitis may explain the stability of their flora; the only study in which a change in the faecal flora in ulcerative colitis was reported found such changes to be confined to patients with diffuse total colitis and severe symptoms. ${ }^{4} \mathrm{~A}$ small number of those with colitis were taking sulphasalazine; the effect of this compound on the faecal flora is not certain. ${ }^{6,16}$ In the present study patients maintained on this drug had faecal flora similar to those with comparable disease who were not receiving antimicrobial treatment.

The relationship between disease activity and the nature of faecal flora in Crohn's disease has not been studied previously. Neither elemental diet (M. H.

\section{References}

1. Miles AA, Misra SS, Irwin JO. The estimation of bactericidal power of the blood. J Hyg 1938; 38: 732-749.

2. Moore WEC, Holdeman LV. Special problems associated with the isolation and identification of intestinal bacteria in fecal flora studies. Am J Clin Nutr 1974; 27 : 1450-1455.

3. Gorbach SL, Nahas L, Lerner PI, Weinstein L. Studies of intestinal microflora. I. effects of diet, age, and periodic
Giaffer, C. D. Holdsworth and B. I. Duerden, unpublished observation) nor corticosteroids ${ }^{4}$ has been shown to affect faecal flora. Keighley et al. ${ }^{5}$ found no correlation between the ileal and colonic flora and the erythrocyte sedimentation rate, seromucoids and serum albumin. In this study, the disease activity in both Crohn's disease and ulcerative colitis was carefully defined by established clinical and laboratory criteria as well as by examination by sigmoidoscope. Of the clinical indices, the CDAI was selected because of its widespread use in clinical trials. Objectivity of this index was greatly enhanced by the use of laboratory measurements that reflect active gut inflammation.

Although the faecal flora in patients with active disease was significantly different from those in the quiescent stage, there was no correlation between the changes in faecal flora and the various clinical and laboratory indices, indicating that the changes in the aerobic flora are non-specific. Patients with active disease tended to have more liquid diarrhoea; the increased number of coliforms may, therefore, represent a non-specific feature of diarrhoeal diseases in general. Particularly relevant to this hypothesis is the fact that radiation enteritis in rats has been found to be associated with increased coliform numbers in the small intestine and faeces. ${ }^{17}$ Similarly, per-oral saline perfusion in normal volunteers has been found to increase the number of aerobes in faeces. ${ }^{4}$

We are grateful to the nursing staff in Ward $J 1$ for helping to deal with the faecal samples, to Mrs Linda Goodwin and Mrs Ann Cooke for their technical assistance and to Mrs C. Bagshaw for her secretarial help. This project was supported by a grant from the Special Trustees of the Former United Sheffield Hospitals. sampling on numbers of fecal microorganisms in man. Gastroenterology $1967 ; 53$ : 845-855.

4. Gorbach SL, Nahas L, Plaut AG, Weinstein L, Patterson JF, Levitan R. Studies of intestinal microflora: fecal microbial ecology in ulcerative colitis and regional enteritis: relationship to severity of disease and chemotherapy. Gastroenterology 1968; 54: 575-587.

5. Keighley MRB, Arabi Y, Dimock F, Burdon DW, Allan RN, Alexander-Williams J. Influence of inflammatory bowel disease on intestinal microflora. Gut 1978; 19 : 1099-1104. 
6. West B, Lendrum R, Hill MJ, Walker G. Effects of sulphasalazine (Salazopyrin) on faecal flora in patients with inflammatory bowel disease. Gut 1974; 15: 960-965.

7. Spiro HM. Clinical gastroenterology, 3rd edn. New York, Macmillan. 1983.

8. Bartholomeusz FDL, Shearman DJC. Measurement of activity in Crohn's disease. J Gastroenterol Hepatol 1989; 4: 81-94.

9. Best WR, Becktel JM, Singleton JW, Kern F. Development of a Crohn's disease activity index. National Cooperative Crohn's disease study. Gastroenterology 1976; 70 : 439-444.

10. Truelove SC, Witts LJ. Cortisone in ulcerative colitis: final report on a therapeutic trial. $\mathrm{Br} M e d J 1955 ; 2$ : 1041-1048.

11. Haenel $H$. Some rules in the ecology of the intestinal microflora of man. J Appl Bacteriol 1961 ; 24 : 242-251.

12. McGeachie J, Kennedy AC. Simplified quantitative methods for bacteriuria and pyuria. J Clin Pathol 1963; 16: 32-38.
13. Rotimi VO, Duerden BI. The development of the bacterial flora in normal neonates. J Med Microbiol $1981 ; 14: 51-62$.

14. Cowan ST. Cowan and Steel's Manual for the identification of medical bacteria. Cambridge University Press. 1974.

15. Duerden BI, Collee JG, Brown R, Deacon AG, Holbrook WP. A scheme for the identification of clinical isolates of gramnegative anaerobic bacilli by conventional bacteriological tests. J Med Microbiol 1980; 13: 231-245.

16. Krook A, Järnerot G, Danielsson D. Clinical effect of metronidazole and sulphasalazine on Crohn's disease in relation to changes in the fecal flora. Scand J Gastroenterol $1981 ; 16: 569-575$.

17. Vincent JG, Veomett RC, Riley RE. Relation of the indigenous flora of the small intestine of the rat to post-irradiation bacteraemia. J Bacteriol 1955; 69 : 38-44. 